\title{
GAMBARAN PERLAKUAN MOBILISASI DINI TERHADAP INVOLUTIO UTERI PADA POST SECTIO CAESAREA DI RUMAH SAKIT UMUM KAB TANGERANG
}

\section{DESCRIPTION OF EARLY MOBILIZATION TREATMENT OF UTERI INVOLUTIO IN POST SECTIO CAESAREA IN GENERAL HOSPITAL OF TANGERANG DISTRICT}

\author{
Suyatini, Endang Suartini \\ Poltekkes Kemenkes Banten \\ Korespondensi: endangkalbar@gmail.com
}

\begin{abstract}
Background this study is still high Postpartum mothers through Sectio Caesarea at Tangerang District General Hospital 2016 (65.9\%) and the implementation of early mobilization by $67 \%$ and not mobilization (33\%) as a problem is whether early mobilization has an influence on the involution uterine postpartum mothers with Sectio Caesarea. The research objective is to obtain an information depiction of early mobilization against involution uterus, results in research can be used by hospitals and other researchers design study a descriptive to look at the picture of early mobilization involution of the uterus research performed in Tangerang District Public Hospital in September to November 2016 population of this study was Postpartum mothers with Sectio Caesarea in Tangerang District General Hospital, while samples were taken using Non-Probability Sampling (Non-Random) using Accidental Sampling with inclusion criteria Postpartum mothers with Sectio Caesarea who were treated for at least 3 days and maternal exclusion criteria Postpartum suffering from Chronic disease, data were collected using observation sheets, data were processed and analyzed by Univariate and Bivariate. Results: Early Showed Mobilization has an impact on involution uteri, discussion connect with expert opinion and factors physiological reproductive and opinions of researchers, the advice was given to the hospital and midwife in the inpatient unit.
\end{abstract}

Keywords: Early Mobilization, Uterine Involution, Pre and Post, Average, Caesarean Section

\begin{abstract}
ABSTRAK
Latar belakang penelitian ini adalah masih tingginya ibu Post Partum melalui Sectio Caesarea di Rumah sakit Umum Kabupaten Tangerang 2016 (65,9\%) dan pelaksanaan Mobilisasi dini sebesar $67 \%$ dan tidak mobilisasi (33\%) sebagai permasalahan adalah apakah mobilisasi dini memiliki pengaruh terhadap Involusi Uteri pada ibu Post Partum dengan Sectio Caesaria. Tujuan penelitian adalah untuk memperoleh informasi
\end{abstract}


gambaran antara mobilisasi dini terhadap Involution Uteri, hasil penelitian ini dapat dimanfaatkan oleh rumah sakit dan peneliti lain. Desain penelitian deskriptif untuk melihat gambaran mobilisasi dini terhadap involution uteri penelitian dilakukan di RSU Kabupaten Tangerang pada bulan September sampai bulan November 2016 populasi penelitian ini adalah ibu Post Partum dengan Sectio Caesarea di Rumah Sakit Umum Kabupaten Tangerang, sedangkan sampel diambil menggunakan Non Probability Sampling (Non Random) dengan menggunakan Accidental Sampling dengan kriteria inklusi ibu Post partum dengan Sectio Caesaria yang dirawat minimal 3 hari dan kriteria eksklusi ibu Post partum yang menderita penyakit Kronis, data dikumpulkan menggunakan lembar observasi, data diolah dan dianalisis dengan Univariat dan Bivariat. Hasil penelitian menunjukan Mobilisasi Dini memiliki dampak terhadap Involution Uteri, pembahasan di hubungkan dengan pendapat pakar dan faktor fisiologis reproduksi serta opini dari peneliti, saran diberikan kepada pihak Rumah Sakit dan bidan di ruang rawat inap.

\section{Kata kunci: Mobilisasi Dini, Involusi Uteri, Pre dan Post, Rerata, Sectio Caesaria}

\section{PENDAHULUAN}

Involusi Uteri adalah proses kembalinya uterus ke keadaan sebelum hamil setelah melahirkan (bobak 2005). Involusi merupakan suatu proses dimana uterus kembali ke kondisi sebelum hamil dengan berat sekitar 60 gram. Pengukuran involusi dapat dilakukan dengan mengukur tinggi fundus uteri, kontraksi uterus dan juga dengan pengeluaran lokia.

Mobilisasi dini adalah kebijakan untuk selekas mungkin membimbing penderita keluar dari tempat tidurnya dan membimbingnya selekas mungkin berjalan. Setelah melahirkan ibu dianjurkan melakukan mobilisasi dini (Sarwono, 2006)

Mobilisasi dini sangat diperlukan ibu nifas agar ibu merasa lebih sehat dan kuat, dapat segera mungkin untuk merawat bayinya, mencegah trombosis dan trombo emboli, melancarkan sirkulasi darah, mencegah terjadinya infeksi masa nifas, kontraksi uterus akan baik sehingga fundus uteri menjadi keras maka resiko terjadinya perdarahan dapat dihindarkan.

Berdasarkan Sumber Demografi Kesehatan Indonesia (SDKI) pada tahu 2012 Angka Kematian Ibu (AKI) Indonesia sebesar $\quad 359 / 100.000$ kelahiran hidup dan AKI Prop Banten pada tahun 2013 adalah 216/100 000 Kelahiran hidup,Sementara target MDGs pada tahun 2015 Indonesia menurunkan AKI menjadi $102 / 100.000$ KH. Penyebab kematian ibu di Indonesia meliputi penyebab obstetri langsung yaitu perdarahan (28\%), 
preeklamsi/eklamsi (24\%), infeksi (11\%). Data di RSU Kab Tangerang pada tahun 2015 mencatat dalam kurun waktu.

Berdasarkan dari Medical Record Rumah Sakit Umum Kabupaten Tangerang didapatkan angka persalinan pada tahun 2014 sebanyak 6.368 persalinan. Persalinan normal sebanyak $3.771(59,2 \%)$ dan persalinan dengan tindakan sebanyak 2.597 (40.8\%). Dari semua kasus jenis tindakan, sectio caesaria merupakan tindakan yang paling banyak yaitu 1.711 (65.9\%) dari 2.597 persalinan dengan tindakan (34.1\%). Berdasarkan studi pendahuluan yang penulis lakukan di ruang anyelir pada tanggal 9-10 $11 \mathrm{mei}$ dari 15 pasien post SC 10 (67\%) orang pasien yang melakukan mobilisasi dini dan $5(33 \%)$ orang tidak melakukan nya.

Tujuan umum adanya penelitian ini diperoleh informasi gambaran pelaksanaan mobilisasi dini terhadap Involutio Uteri Pada Post Sectio Caesarea Di Rumah Sakit Umum Kabupaten Tangerang Pada Tahun 2016. Adapun tujuan khusus meliputi : mengidentifikasi involusio uteri pada ibu Post SC setelah diberi perlakuan mobilisasi dini hari pertama, mengidentifikasi involusio uteri pada ibu post SC setelah diberi perlakuan mobilisasi dini hari kedua, mengidentifikasi involutio uteri pada ibu post SC setelah diberi mobilisasi dini hari ketiga.

\section{METODE}

Desain penelitian ini adalah deskriptif untuk melihat gambaran pelaksanaan mobilisasi dini terhadap involutio uteri. Populasi dalam penelitian ini adalah seluruh ibu post partum dengan sectio Caesaria yang di rawat di Rumah Sakit Umum Kabupaten Tangerang sedang sampel diambil dengan menggunakan non probality sampling/non Random menggunakan accidental sampling. Sampel adalah total pulasi seluruh pasien yang dirawat di rumah sakit umum Tangerang pada September s/d November selama penelitian dilakukan sebanyak 52 responden.

Kriteria Inklusi meliputi ibu Nifas Post SC yang bersedia menjadi responden yang dirawat Rumah Sakit Umum Kabupaten Tangerang, ibu nifas Post SC dirumah sakit umum Kabupaten Tangerang, ibu post SC dirawat di RSUKab Minimal 3 hari. Kriteria Ekslusi meliputi Ibu post partum yang memiliki penyakit kronis. 
Penelitian dilakukan di ruang nipas RSU Kab Tangerang pada bulan September - November 2016.

Data didapatkan dengan cara responden di ukur tinggi fundus uteri dan di catat pada instrument pengumpulan data, responden dilakukan mobilisasi dini, responden di pandu untuk melakukan mobilisasi pada masa 6-24 jam setelah operasi SC, responden pada hari ke 3 (tiga) dilakukan pemeriksaan involusi uterus yang meliputi pemeriksaan tinggi fundus uteri dan pengeluaran lokia dengan menggunakan lembar observasi.

Analisa data meliputi analisa univariat untuk mengetahui statistik deskriptif dari masing - masing variabel mobilisasi dini dan involusio uteri pada kelompok numerik dilihat distribusi frekuensi meliputi mean, median, modus dari tinggi fundus uteri dan pengeluaran lochea pada hari ke 3 .

\section{HASIL DAN PEMBAHASAN}

Penelitian dilaksanakan di Rumah Sakit Umum Kabupaten Tangerang pada bulan November tahun 2016, yang di jadikan sampel adalah ibu yang melahirkan dengan section Caesaria adapun hasil penelitian sebagai berikut :
Tabel 1. Distribusi Responden

Di RSU Kabupaten Tangerang Tahun 2016

\begin{tabular}{lcc}
\hline Responden & Frekuensi & Presentase \\
\hline Mobilisasi & 36 & 69,2 \\
\hline In & 16 & 30,8 \\
mobilisasi. & & \\
\hline Jumlah & 52 & 100 \\
\hline
\end{tabular}

Berdasarkan Tabel 1 terlihat bahwa responden yang di jadikan kasus atau mendapat intervensi sebanyak 36 responden $(69,2 \%)$ sedang sebagai yang tidak mendapat intervensi sebanyak 16 responden $(30,8 \%)$

Tabel 2. Distribusi Rerata Responden

Selama Tiga Hari Pasca Mobilisasi

Terhadap Involution Uteri

\begin{tabular}{lccc}
\hline Responden & $\begin{array}{r}\text { Hari } \\
\text { ke 1 }\end{array}$ & $\begin{array}{r}\text { Hari } \\
\text { ke 2 }\end{array}$ & $\begin{array}{c}\text { Hari } \\
\text { ke 3 }\end{array}$ \\
\hline Mobilisasi & 1,94 & 2,74 & 3,81 \\
\hline In & 1,75 & 1,98 & 2,25 \\
Mobilisasi & & & \\
\hline
\end{tabular}

Berdasarkan tabel 2, terlihat Rerata Tinggi fundus uteri pada mobilisasi hari pertama, kedua dan ketiga baik yang dilakukan mobilisai ataupun yang in mobilisai terlihat ada kenaikan, pada post SC, yang dilakukan mobilisasi hari pertama 1,94, hari kedua 2,74 dan hari 
ketiga 3,81 \{range 1,87$\}$ sedangkan yang tidak dilakukan mobilisasi hari pertama 1,75 , hari kedua 1,98 dan hari ketiga $2,25 \quad$ range 0,50$\}$ artinya perlakuan mobilisasi memliki pengaruh terhadap involution uteri.

Berdasarkan hasil penelitian didapatkan Rerata Tinggi fundus uteri pada mobilisasi hari pertama, kedua dan ketiga baik yang dilakukan mobilisai ataupun yang in mobilisai terlihat ada kenaikan pada post SC, yang dilakukan mobilisasi hari pertama 1,94, hari kedua 2,74 dan hari ketiga 3,81 range 1,87 \} sedangkan yang tidak dilakukan mobilisasi hari pertama 1,75 , hari kedua 1,98 dan hari ketiga 2,25 \{range 0,50 artinya perlakuan mobilisasi memliki pengaruh terhadap involution uteri.

Menurut Cafernito 2007 menyatakan mobilisasi dini merupakan upaya untuk selekas mungkin membimbing ibu post partum dari tempat tidur dan membimbing untuk berjalan, mobilisasi dini merupakan aspek terpenting pada fungsi fisiologis tubuh karena hal itu sangat essensial untuk mempertahankan kemandirian ibu. Mobilisasi dini menurut Siregar 2009 adalah upaya untuk menggerakan tubuh dari satu tempat ke tempat lain secara bertahap dan di berilak langsung setelah melahirkan.

Menurut Cafernito 2007 melalui mobilisasi dini akan dapat melancarkan pengeluaran Lokhea dan mengeluarkan sisa darah melalui jalan lahir, mobilisasi dini juga dapat mencegah infeksi post partum apabila involusio uterus tidak berjalan dengan baik sehingga sisa darah dan plasenta tidak dapat di keluarkan, disamping itu mobilisasi dini mampu mempercepat involution alat kandungan sehingga memperlancar pengeluaran sisa-sisa dari dalam uterus, kontraksi uterus akan membaik sehingga proses kembalinya Rahim ke semula akan berjalan dengan baik.selain itu dengan mobilisasi dini akan merangsang peristaltic usus dan kandung kemih sehingga akan membantu mempercepat organ tubuh bekerja seperti semula sehingga ibu merasa lebih baik dan lebih Kuat (Mucktar 1995).

Selanjutnya Chapman, 2006 memaparkan Faktor-faktor yang mempengaruhi Mobilisasi dini adalah rendahnya pengetahuan ibu bersalin tentang manfaat mobilisasi, kecenderungan pengetahuan baik terhadap sesuatu masalah yang dihadapi maka ibu akan bersikap positip terhadap 
masalah tersebut. Tinggi nya pengetahuan seseorang akan berpengaruh terhadap respond dan taggapan terhadap suatu obyek/mobilisasi (Notoatmodjo, 2003) . Ketidakmampuan fisik dan mental, Persalinan merupakan proses yang melelahkan saat persalinan ibu menggerakaan seluruh tenaganya untuk melewati proses yang panjang sehingga ibu sering menjadi malas dan tidur dari pada melakukan suatu gerakan.

Nyeri dan rasa tidak nyaman setelah melahirkan sering membuat ibu enggan untuk melakukan mobilisasi, kecemasan ibu untuk melakukan mobilisasi dini sangat berpengaruh terhadap tingkat keberhasilan.

Menurut Siregar 2009, yang penting di perhatikan dalam mobilisasi dini adalah rasa percaya diri dari ibu untuk dapat melakukan mobilisasi dini dengan cepat, mobilisasi dilakukan sesegera mungkin dengan cara yang benar akan dapat mempercepat pemulihan, mobilisasi tidak akan menyebabkan jahitan lepas, mobilisasi dilakukan secara bertahap agar semua system sirkulasi tubuh dapat menyesuaikan diri untuk berfungsi secara normal, tetap memperhatikan pola nutrisi, nutrisi yang baik akan membantu ibu dalam mobilisasi dan involution uteri, penambahan energy /nutrisi akan menujang proses kontraksi Uterus pada proses Involutio Uteri menuju normal, apabila kekurangan gizi atau nutrisi maka kontraksi tidak maksimal sehingga involution uteri berjalan lambat.

Faktor laktasi atau pengeluaran ASI juga berpengaruh terhadap kontraksi uterus sehingga dapat mengurangi perdarahan.

Dengan Mobilisasi dini maka kontraksi uterus akan berjalan dengan baik sehingga resiko perdarahan dapat di hindari dan proses dimana uterus kembali ke kondisi sebelum hamil akan terwujud.

Pelaksanaan Mobilisasi terhadap ibu post partum di Rumah Sakit Umum Kabupaten Tangerang di laksanakan oleh tenaga bidan dan Nakes lainnya dengan pendampingan ibu post partum, petugas yang melaksanakan kegiatan Mobilisasi harus memiliki beberapa kriterian tetentu agar hasil sesuai dengan yang di harapkan berdasarkan SOP yang telah ada, menurut Gybson 1997 perilaku seseorang untuk bekerja sesuai dengan hasil yang diharapkan di pengaruhi oleh factor individu meliputi (kemampuan dan keterampilan petugas 
sesuai dengan peran pungsinya, pengalaman bekerja di instansi tersebut, umur dan tingkat social dari petugas) dan factor organisasi (kepemimpinan struktur organisasi, desain pekerjaan, supervise dan imbalan) serta factor psikologi diantaranya (sikap, kepribadian, motivasi dan persepsi petugas).

\section{SIMPULAN}

Berdasarkan hasil penelitian dimana Mobilisasi dini pada ibu post partum dengan SC memiliki dampak terhadap involution Uteri di Rumah Sakit Umum Kabupaten Tangerang pada tahun 2016 maka dapat di simpulkan sebangai berikut, pelaksanaan mobilisasi dini terhadap ibu post Partum dengan SC di rumah sakit umum kab tangerang telah berjalan dengan baik sesuai dengan SOP yang telah ada.

\section{UCAPAN TERIMA KASIH}

Penulis mengucapkan terima kasih kepada Poltekkes Kemenkes Banten yang telah mendanai penelitian ini.

\section{DAFTAR PUSTAKA}

Azwar A dan Prihartono, 1987; Metodologi Penelitian Kedokteran dan Kesehatan Masyarakat, Bina Aksara Jakarta.
Arikunto S,2010 ; Manajemen Penelitian, Rineka Cipta, Jakarta.

Depkes RI, 2009 ; Rencana Pembangunan Jangka Panjang Bidang Kesehatan, Jakarta

Depkes RI, 1997 ; Pedoman Administrasi Pengelolaan Program Pendidkan Diploma III Kesehatan, Jakarta.

Bobak. Loedermilk. Jensen. 2004. Buku Ajar Keperawatan Maternitas. Edisi 4. Jakarta : EGC.

Mitayani. 2013. Asuhan Keperawatan Maternitas. Jakarta : Salemba Medika.

Mochtar, R. 2011. Sinopsis Obstetri. Jilid 1, Edisi 3. Jakarta : EGC.

Nurarif, Amin Huda. 2015. Aplikasi Asuhan Keperawatan Berdasarkan Diagnosa Medis dan Nanda Nic Noc. Edisi Revisi Jilid 1. Jogjakarta : Mediaction.

Reeder, Sharon. 2011. Keperawatan Maternitas. Edisi 18, Volume 2. Jakarta : EGC.

Saifuddin, AB. 2010. Buku Panduan Praktis Pelayanan Kesehatan Maternal dan Neonatal. Edisi 1 Cetakan 12. Jakarta : Pt Bina Pustaka Sarwono Prawirohardjo. 
Saifuddin, AB. 2010. Ilmu Kebidanan Sarwono Prawirohardjo. Edisi Keempat. Jakarta : Pt Bina Pustaka Sarwono

Prawirohardjo.

Winkjosastro, H. 2010. Ilmu Bedah Kebidanan. Jakarta : Pt Bina Pustaka Sarwono Prawirohardjo. 